\title{
Research on Local Culture based on Landscape Design of Characteristic Town
}

\author{
Zhou Juan ${ }^{1}$, Zeng Xinyi ${ }^{2}$ \\ ${ }^{1}$ Applied Science College of Jiangxi University of Science and Technology, Ganzhou, Jiangxi Province \\ ${ }^{2}$ Applied Science College of Jiangxi University of Science and Technology, Ganzhou, Jiangxi Province
}

\begin{abstract}
In the construction of characteristic towns, "rural, homesickness, context, inheritance, and development" has been mentioned by people. How to pay attention to ecological nature, focus on local culture, and inherit the cultural context is the key to today's landscape space design. Taking Longquan city as the research object, through combing and refining the local culture elements, this paper designs a scheme through the concept of "Rongqing" characteristic town landscape, and explores the way to arouse homesickness with the help of design symbols and the integration of tradition and modernity to realize the recurrence of local culture.
\end{abstract}

\section{LOCAL CULTURE CHARACTERISTIC TOWN}

As an element of landscape design, local culture is the uniqueness of a place, which can give human deep memory and distinct impression, and as well as a special cultural memory symbol. In fact, local culture is a kind of "homesickness" about nature, cultural activities, hometown, childhood memories, and is also the common memory of a group that can impress people. This kind of "cultural symbol" shows individuality and subjectivity in individuals but expresses a common "homesickness culture" in social groups living together.

The characteristic town can be regarded as a place to inherit and display unique local culture, while culture itself is the "soul" of these "characteristics". it is a complex set ${ }^{[1]}$ of "history, geography, local customs, traditional customs, lifestyle, literature and art, behavior norms, thinking mode, and values" of the town. Landscape design of characteristic towns with local cultural connotation can arouse people's cultural awareness and promote the protection and inheritance of culture.

\section{THE REFINEMENT OF LOCAL CULTURAL ELEMENTS}

\subsection{Historical review}

Longquan is known as "the capital of Celadons and the land of swords ". By textual research, Longquan is the birthplace of the Celadons of Ge Kiln (called the five famous kilns in Song Dynasty together with Guan Kiln, $\mathrm{Ru}$ Kiln, Ding Kiln, and Jun Kiln) and the birthplace of Chinese Celadons, so it is called "the capital of Celadons"[2]. Since the Yuan Dynasty, as important export commodities, Longquan Celadons have become a business card for the world to understand China. Longquan is also famous for its swords. Longquan sword has the characteristics of "sharp, hard and soft, cold, and exquisite patterns". It is the representative of ancient Chinese weapons. Li Bai, the poet immortal, once wrote a poem: "how can people in the world know the common people with a Longquan sword on the waist". In 2006, both the firing technique of Longquan Celadons and the forging technique of Longquan swords became the first group of representative works of national intangible cultural heritage ${ }^{[3]}$. With the passage of time and the precipitation of history, Longquan City has given birth to profound historical and cultural deposits, which have also laid the foundation for the construction of the characteristic town.

\subsection{Local customs}

In Longquan, people pay special attention to the customs of the year, such as the dragon Lantern Festival on the 15 th day of the first month in Shima village, orchids Festival in the Spring Festival, dragon dance Festival in the Lantern Festival in Anren Town, kite flying in Qingming Festival, temple fair in Mao mountain, dragon boat race in Longyuan Town, temple fair in Fengyang mountain, moon appreciation in Mid Autumn Festival, climbing on Chongyang mountain, exhibition of celadons and swords, dust removal in the twelfth month, and Spring Festival couplet on New Year's Eve. These customs are inherited over the years and remain unchanged, with a strong local cultural connotation.

\subsection{Cultural heritage}

Since ancient times, Longquan City has been prosperous 
in culture. Ye Shaoweng, a poet of the Southern Song Dynasty who wrote "the garden is full of beauty, a spray of red apricot is blooming by the wall", was born here. According to historical records, there were 248 scholars in Longquan from the Tiansheng period of the Northern Song Dynasty to 1251 of the Xianchun period of the Northern Song Dynasty, which became a great spectacle in the history of imperial examination ${ }^{[4]}$. Longquan's profound cultural heritage has made it a cultural Longquan. According to the investigation and research, there are a large number of rural culture halls in Longquan City, which have the functions of learning, teaching, etiquette, and entertainment. This also makes the celadon culture, sword culture, filial piety culture, ecological culture, bamboo culture, and other characteristics of local culture to be better inherited and developed.

\subsection{Corridor-bridge culture}

Corridor-bridge is a common rural image in the mountainous area of southern Zhejiang. It is also known as a house bridge or wind-rain bridge. Usually, the upper part of it is a gallery house, and the lower part is a bridge. According to historical records, there was a Jichuan bridge in the ancient Longquan, which crossed the river and connected the north and the south with more than 200 meters long and was called "the first corridor-bridge in China" for 72 gallery houses on the bridge. There are only a few existing corridor-bridges in the world. According to the survey, there are 18 main corridor-bridges in Longquan, most of which are wooden arch bridges. Among them, there are 42 gallery houses on Yonghe Bridge, which is the best and longest corridor bridge existing in Zhejiang Province. Corridor-bridge is the epitome of the folk customs in Longquan. Many corridor bridges have shrines, which are the places where villagers worship their ancestors' gods. The bridge records, inscriptions, couplets, poems, sculptures, gallery paintings, and calligraphy ${ }^{[5]}$ on the bridges also make them have more cultural connotation.

\subsection{Bamboo culture}

"If there is bamboo in the mountain, it will be green". The green bamboo sway with the wind and dance in the twinkling light; "If there is bamboo near the water, it will be green". The refreshing breeze blows the green and cold waterside, creating a sparkling, elegant, and quiet scene. The rural landscape of Longquan presents a beautiful spatial effect just like this. People's love for bamboo has accumulated over time in Longquan. They plant, use, and appreciate bamboo. In daily life, bamboo products can be seen everywhere, such as bamboo shoulder pole, big grain basket, dustpan, bamboo broom, chicken and duck cage, fishing utensils, fire cages (bamboo woven heating appliances), bamboo chairs and benches, bamboo mats, firecrackers, chopsticks, chopsticks, chopsticks tube, etc. ${ }^{[6]}$, which have already formed the unique bamboo culture of Longquan.

\subsection{Local architectural features}

Influenced by Hui style architecture, most of Longquan vernacular architecture adopts the Huizhou style. There are several common styles: Double-eaves structure based on a wooden frame. To prevent the erosion of wood wall by rain, the eaves are usually designed very deep, and there is few front eaves wall. The gables on both sides are earth walls or stone walls ${ }^{[7]}$; The roof of the building is overhanging gable roof and hard-top. The outer wall is made of soil, brick, and stone, and the interior is of a wooden frame structure.

\section{CONCEPTION OF LANDSCAPE CONCEPT DESIGN OF "RONGQING" CHARACTERISTIC TOWN}

\subsection{Location overview}

The location of the landscape concept design of "Rongqing" Characteristic Town is in Shangyang Town, the west of Longquan City, 36 kilometers away from the center of Longquan City. Shangyang is a beautiful place with profound cultural heritage and unique tourism resources, especially porcelain clay resources. A saying goes, "Longquan celadon has attracted worldwide attention, and Shangyang celadon is well known". Shangyang is also the birthplace of the intangible cultural heritage of mankind, "traditional firing techniques of Longquan celadon". the site is adjacent to the celadon Research Institute and Longquan celadon factory. There are several sites of the ancient kiln. All kinds of construction facilities are relatively perfect, and the overall location advantages are obvious in this place.

\subsection{Design Strategy}

\subsubsection{Improve infrastructure with the people-oriented principle}

The original road organization of the site is chaotic, with mixed motorways, non-motorized lanes, sidewalks, public toilets, rest facilities, and guidance facilities. In addition, the public rest space is too chaotic and has not been partitioned. The function of each space fails to play well. Therefore, we should pay attention to the construction of infrastructure, highlight the people-oriented design, combine road width, step height, plant density, size of buildings and structures, light cooling and heating and other situations, consider the barrier-free design for special groups and the safety protection design for children, strive to improve the public infrastructure in different functional divisions and landscape nodes and build landscape space for various groups of people.

3.2.2 Pay attention to cultural connotation with the combination of landscape experience 
The service object of the characteristic town is people. Therefore, to meet the needs of different tourists, different tour routes should be set as much as possible to give diversified choices. In the scheme design, celadon culture, corridor bridge culture, bamboo culture, and its subsidiary culture endow the town with cultural connotation and uniqueness. In the design, we can pursue the interaction between people, scenery, and culture from different perspectives, such as local culture experience, natural landscape sightseeing, scientific research, ecological leisure, and health care, to better integrate the local culture into the landscape design. At the same time, the use of landscape design and other methods to make the landscape as beautiful as possible to enhance the visual effect.

\subsubsection{Enhance the connection of various spatial layouts}

There are some problems in the original scenic spots of the site, such as scattered layout, lack of route planning organization, imperfect supporting facilities, and weak spatial connection. Combined with the needs for sustainable development of characteristic towns, this design should pay attention to the continuity of space, creating a place with spatial sequence changes and presenting a unique local cultural atmosphere. It is not only the continuity of space but also the continuity of space and time, that is, various kinds of connections generated in the actual use of the site. This design can use view borrowing, opposite scenery, obstructive scenery, en-framed scenery, perspective scenery, referring scenery, reflecting scenery and other traditional landscape architecture methods, separate and connect space with the help of king wall, scenery frame, porch, and height difference to make spaces have reasonable function layout, a clear theme, close connection, and mutual extension.

\subsubsection{Re-inject space vitality by integrating new and old things}

The site is mainly composed of dense, low-density buildings, mostly residential buildings with 2 or 3 floors. At the same time, some of the ancient brick and tile buildings are preserved, presenting as single-story houses with green bricks and white walls. Due to the mixed styles, the overall style is fuzzier, which also destroys the overall landscape to a certain extent. Therefore, to integrate the style and better show the theme, various elements are integrated into the design, and the overall architectural keynote is defined as a simple, pure, and simple Chinese style with Zen. The materials should be selected from the local common Chinese traditional materials such as tiles, broken porcelain, yellow clay, red brick, bluestone slab and bamboo strips to build an overall tone of new Chinese landscape space. On the one hand, through the refinement, deconstruction, and reorganization of the elements reflecting the local cultural connotation, it can arouse the resonance of local feelings in the treatment of ground pavement patterns. On the other hand, through the combination of wood plastic composite materials, new metal materials, transparent concrete, building glass, membrane structure and other new materials, the local cultural elements and modern elements are organically integrated, which makes the whole space more visual, more in line with the contemporary aesthetic, and also brings more possibilities for design creativity.

\section{CONCEPTUAL LANDSCAPE DESIGN SCHEME OF "RONGQING" CHARACTERISTIC TOWN}

\subsection{Landscape spatial layout}

The overall layout of the design presents a progressive style of free layout. In the space, the form of "curve-grid-rectangle" is used to combine points, lines, and surfaces. The overall planning is divided into four functional levels, including plant layer, landscape layer, building layer, and pavement layer. According to the spatial sequence, there are 17 landscape points. Through the construction of linear street and point space, the design strives to create a combination of dynamic and static, leisure appropriate space effects.

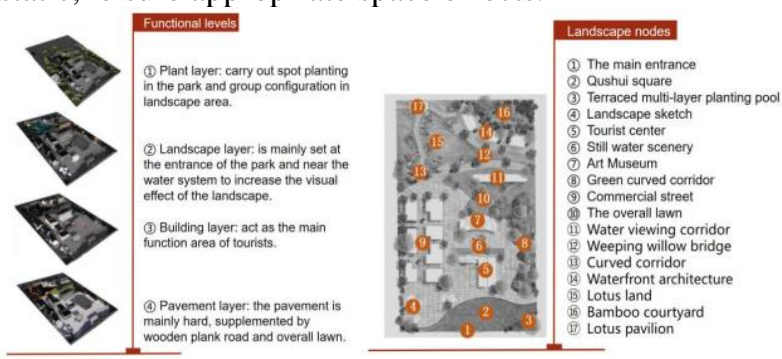

Figure.1. Landscape spatial layout

\subsection{Landscape route analysis}

The whole landscape route is orderly unfolded by taking "the main entrance - Qushui square - tourist center - still water scenery - Art Museum - water viewing corridor landscape" as the axis; taking commercial block, curve corridor rest area and landscape experience area as three centers, namely, "one axis and three centers", presenting a spatial effect with both traditional culture charm and modern landscape interest. The entrance adopts open design, with landscape sketch and ground pavement for space guidance to distinguish different path selection. Tall trees are planted on both sides of the road to increase the sense of hierarchy of space, and different paving materials and landscape devices are used to make the path continue and distinguish. In the landscape experience area, gallery roads and curved corridors are used to guide the walking route and expand the spatial sequence.

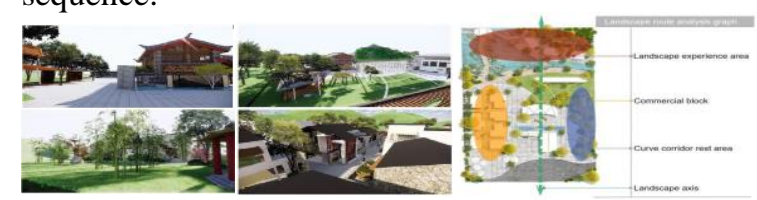

Figure.2.Landscape route analysis 


\subsection{Analysis of plant planting}

From the perspective of respecting original ecological culture, the design is conducive to create an original and simple spacial effect. By adopting the natural planting method, macrophanerophytes, shrubs, terram operimentums are reasonably matched to present a planting effect of landscape plants with a sense of layering. To better display the local cultural connotation, arouse emotional resonance and "homesickness", the plant configuration is mainly local plants, with appropriate ornamentation of exotic plants. The tree layer is mainly composed of Syzygium jambos, Cinnamomum camphora, willow, Sweet Olive, Lagerstroemia indica, Acer palmatum; The bush layer is mainly composed of Queensland umbrella tree, Ficus microcarpa, Common Nandina, Serissa japonica, Euonymus macrophylla; The acuatic plants is mainly composed of Lotus flower, Thalia dealbata and so on.

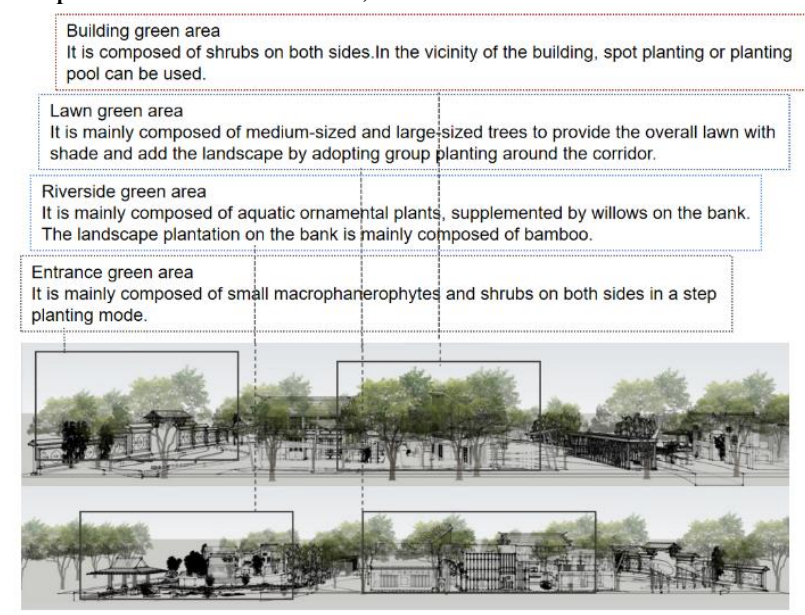

Figure.3.Plant planting analysis

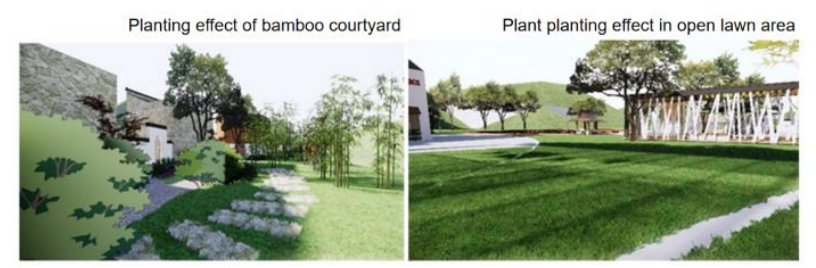

Figure.4.Effect of plant planting

\subsection{The construction of local cultural landscape image}

\subsubsection{Representation of architectural image}

By referring to the local architectural style of Longquan in southern Zhejiang Province, according to the modern functional requirements and local climate conditions, the architectural design carefully adopts modern architectural methods and explores innovation based on inheriting local architectural culture. The building adopts a single eave and a new Chinese style. The shops shall be vertical to the street to the full and tiled along the depth to form a building plane with a wide facade and large and deep internal space. The shop shall have less decoration on the street surface, and the window lattice, cornice, and davit shall be kept generous and tidy as far as possible. Through the deep excavation of local architecture, bamboo weaving skills, celadon modeling, and other aspects of Longquan, as well as refining and simplifying on the traditional basis, combined with the original nature of local culture, the design pursues the transformation of form to make it have a modern style. The local common tiles, broken porcelain, yellow clay, red brick, green stone slab, and bamboo strips are selected to present the local architecture with natural and simple texture and artistic decorative aesthetic feeling, reflecting the irreplaceable nature of local culture in architecture.

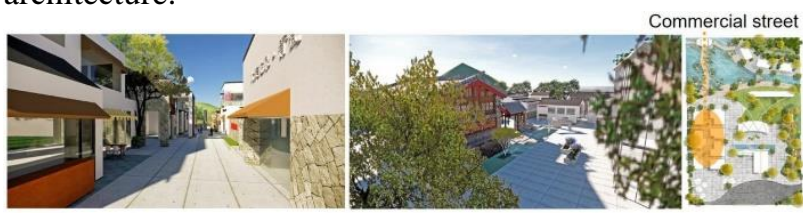

Figure.5.Design sketch of the architectural image reproduction scheme

\subsubsection{Representation of cultural image}

Cultural image is a kind of specific cultural symbol, which can be presented with the help of specific design representation. In this scheme, landscape sketches, exterior wall decoration, ground pavement, entrance image, text symbol are all used to express the Celadon culture, bamboo culture, and architectural culture of Longquan. In terms of landscape color, the main tone is green, white, earth red, and mud yellow. Materials that can reflect the simple and elegant texture are selected to strive for the simple and implicit characteristics of the Shangyang area in Longquan.

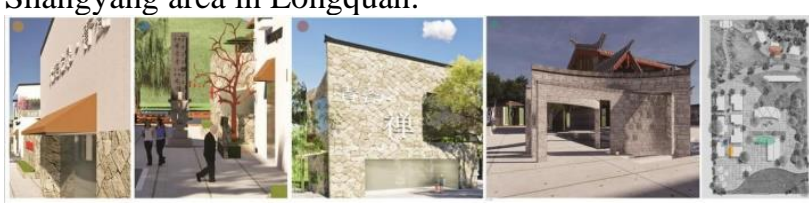

Figure.6.Design sketch of representation of the cultural image

\subsubsection{Representation of the corridor-bridge image}

The overall shape of the curved corridor surrounded by lawn extracts the design elements of the "corridor bridge" in Shanglong, metaphorizes it as "corridor bridge" by means of deconstruction and reorganization, and metaphors the large area of lawn as "water" to reproduce the image of corridor bridge. The main material for the facing material of the corridor bridge is "wood", which can create a sense of nature and simple. The original bamboo pole is painted white and inserted obliquely to highlight a sense of spatial rhythm. Under the sun, the mottled light and shadow projected by the green lawn form the virtual and real contrast of space. Through the design method of the shadow scene, the overall space has a more visual appreciation effect. 


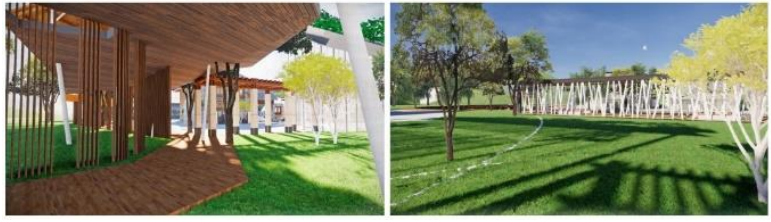

Figure.7.Design sketch of representation of the corridor-bridge image

\section{CONCLUSION}

The representation of "local culture" in the landscape design of a characteristic town should create a place integrating modern and local culture and enhance people's sense of identity and belonging based on the assurance of overall design style. Architectural forms derived from historical context, local plants, cultural deposits, and cultural connotations are the source of inspiration for the landscape design of a characteristic town. We should be aware that only the deconstruction and reorganization of local culture, the extension and inheritance of historical context, and the collision and integration of tradition and modernity can make the characteristic town radiate new vitality. The research on how to construct the display space of local culture, retain homesickness for people and continue the "collective memory" through ways like integrating local elements, enriching cultural connotation, arousing emotional resonance, and realizing context continuity, has practical significance for the landscape design of characteristic towns.

\section{REFERENCES}

1. Zhao Junxiang, Cultural Heritage in the Process of Urbanization in China[J], Journal of Shandong University(Philosophy and Social Sciences), 2014(04), PP.34-43.

2. Wang Zehe, Research on the Characteristics and Artistic Charm of Longquan Celadon[J].China Daily, 2018(3), pp.31-32.

3. Zheng Jing, Study on the Development Strategy of Ecotourism in Late Developing Areas-A Case of Longquan City[D], Zhejiang Normal University, 2016.

4. Lu Jinsong, Research on the Evaluation and Development Countermeasures of Ecotourism Landscape Resources in Longquan City[D], Zhejiang A\&F University, 2011.

5. Hu Pei, Research on Protection and Development of Lishui Corridor-bridge[J], The Urban Construction Archives Magazine, 2014(2), PP.10-12.

6. Cai Minhua, Research on the Ecological Culture Tourism of Lishui in Southern Zhejiang Province based on the Advantages of Bamboo Industry[J], Journal of Bamboo Research, 2008(4), PP.58-62.

7. Lan Faqin, Research on the Architectural Art of Baoxi Bamboo in Longquan from the Perspective of
New Vernacular Design[J], Journal of Lishui University, 2018(4), PP.97-101. 